\title{
Partial Dissociation and Hydration Quantitatively Explain the Properties of Aqueous Electrolyte Solutions and hence Empirical Activity Concepts are Unnecessary
}

(Dedicated to Svante Arrhenius on the occasion of IYC 2011)

Raji Heyrovska

Institute of Biophysics, Academy of Sciences of the Czech Republic, 135 Kralovopolska, 61265 Brno, Czech Republic. Email: rheyrovs@ hotmail.com

\begin{abstract}
The author shows that Arrhenius's theory of partial electrolytic dissociation was immaturely displaced about eight decades ago by the empirical concept of ionic activities and the assumption of complete dissociation of electrolytes at all concentrations. The latter brought the theory of electrolytes over the next decades into a complicated state without any physical significance. Therefore, the author started a systematic investigation of the available data and could complete restore the original theory of partial dissociation. Now solution properties can be easily understood and quantitatively explained in terms of absolute concentrations and volumes of ions and ion pairs and hydration.
\end{abstract}

\section{Introduction}

Common table salt, also called the Divine substance (1), has been an indispensable ingredient in our daily lives for many centuries. However, a proper insight into its properties in aqueous solutions has intrigued the minds of many. It is only at the end 
of the nineteenth century that Arrhenius $(2 a, b)$ made a big leap forward when he suggested that ".. electrolytes, when dissolved in water, become to varying degrees split or dissociated into electrically opposite positive and negative ions. The degree to which this dissociation occurred depended above all on the nature of the substance and its concentration in the solution" $(2 b)$.

Several biographies of Arrhenius can be found in $(2 b, d, 3,4)$. To quote from a recent tribute to Arrhenius (4), "Svante Arrhenius was an extremely talented man with an expansive range of interests, both inside and outside the academic domain. His early work with the dissociation of ionic substances, which was presented in his doctoral thesis (1884), earned him the Nobel Prize in Chemistry in 1903, twenty years after his first ideas in this area had been presented orally to a very sceptical and even scornful academic supervisor." Arrrhenius was awarded the Nobel Prize "in recognition of the extraordinary services he has rendered to the advancement of chemistry by his electrolytic theory of dissociation", (5).

Arrhenius' theory of partial dissociation helped to explain the properties of dilute electrolyte solutions based on his idea that the conductivity ratio (which is ratio of the conductivity at a given concentration to that infinite dilution) could be used as a measure of the degree of dissociation. Solution theory began to flourish and was developing well on this basis in the earlier decades of twentieth century. While researches were continuing to find ways of extending the theory to concentrated solutions, the seeming failure of the conductivity ratio in explaining the Guldberg and Waage's law (6), gave rise to an 'interim' thermodynamics based on the empirical concepts of activities, activity and osmotic coefficients (7). Since this was seemingly supported by the theory of interionic interaction between free ions $(8)$ for dilute solutions with nearly completely dissociated electrolyte, the latter was assumed to be 
valid for all concentrations and the idea of partial electrolytic dissociation was soon dropped, despite protests by many (9).

However, over the next few decades, explanation of the properties of solutions based on the empirical concepts of activity and osmotic coefficients and the idea of complete dissociation at all concentrations, amounted to converting painstaking data into more and more elaborate parametric equations to fit the data for higher and higher concentrations with less and less physical significance as noted by many (10). Moreover, there was no unified explanation of the cause of non-ideality of solution properties for the whole range of concentrations.

On realizing that this clearly pointed to some conceptual errors in the development of solution chemistry, the present author systematically started re-investigating the available experimental data. It became evident gradually (11-13) that it was actually an unfortunate turn in solution chemistry to have prematurely abandoned the theory of partial electrolytic dissociation founded by Arrhenius.

This article shows briefly how partial dissociation and hydration are the two main causes of the non-ideal physicochemical properties of strong electrolyte solutions over the entire concentration range from zero to saturation. The series of papers in the last few decades leading to the above conclusion can be found in (11-13). The full text of the plenary talk (12) contains the relevant tables of data for many strong electrolytes, figures and a complete list of the main references. Additional tables of supporting data can be found in (13). This article brings all the important main results together in favor of partial dissociation and hydration of electrolytes. Note: In the text below, equations based on partial dissociation and hydration are marked in green and those based on empirical activity and the assumption of complete dissociation in orange/amber. 


\section{Brief account of Arrhenius' theory of partial electrolytic dissociation}

Arrhenius (2) put forth the pioneering idea that "all electrolytes in an extremely dilute state are completely active" (by active, he meant ionic due to dissociation). Taking for example the neutralization reaction of $\mathrm{HCl}$ with $\mathrm{NaOH}$ to form $\mathrm{NaCl}$ and water, he suggested $(2 b)$ the following equations,

$$
\begin{aligned}
& \left(\mathrm{H}^{+}+\mathrm{Cl}^{-}\right)+\left(\mathrm{Na}^{+}+\mathrm{O} \mathrm{H}^{-}\right)=\left(\mathrm{Na}^{+}+\mathrm{Cl}^{-}\right)+\mathrm{H} \mathrm{OH} \\
& \mathrm{H}^{+}+\mathrm{OH}^{-}=\mathrm{HOH}
\end{aligned}
$$

He thus explained the heat of neutralization, which is independent of the nature of the acid and base, as due to the formation of water from the ions, $\mathrm{H}^{+}$and $\mathrm{OH}^{-}$.

From his experiments on electrical conductivity $(2 a)$, supported by Ostwald's (14) theory of dilute solutions and van't Hoff's (15) results on the osmotic pressures of electrolyte solutions, he concluded that in dilute solutions of concentration M (moles per liter of solution), there exists the equilibrium, (using $\mathrm{NaCl}$, as a typical example of a strong electrolyte),

$$
\begin{aligned}
& \mathrm{NaCl}<==>\mathrm{Na}^{+}+\mathrm{Cl}^{-} \\
& (1-\alpha) \mathrm{M}<==>\alpha \mathrm{M}+\alpha \mathrm{M}
\end{aligned}
$$

where, $\alpha$, the degree of dissociation is the fraction of one mole of $\mathrm{NaCl}$ which dissociates into $\alpha$ mole each of $\mathrm{Na}^{+}$and $\mathrm{Cl}^{-}$ions and (1- $\left.\alpha\right)$ is the fraction that is left undisoociated (stays in inactive electrically neutral state). The total molar concentration of the solute is the sum, $(1-\alpha) \mathrm{M}+2 \alpha \mathrm{M}=(1+\alpha) \mathrm{M}=\mathrm{iM}$, where $\mathrm{i}=$ $(1+\alpha)$, the factor found by van't Hoff in the equation for osmotic pressure $\left(\pi_{\mathrm{os}}\right)$, 
$\pi_{\mathrm{os}}=\mathrm{iMRT}$

at concentration $\mathrm{M}$ and temperature $\mathrm{T}$ in Kelvins and $\mathrm{R}$ is the molar gas constant.

The dissociation constant, as per the Guldberg and Waage's law (6) (or the law of mass action for a reversible reaction in equilibrium) is given by

$\mathrm{K}_{\mathrm{c}}=\left[\mathrm{Na}^{+}\right]\left[\mathrm{Cl}^{-}\right] /[\mathrm{NaCl}]=(\alpha \mathrm{M})^{2} /(1-\alpha) \mathrm{M}=\alpha^{2} \mathrm{M} /(1-\alpha)$

On using for $\alpha$ the conductivity ratio $\left(\Lambda / \Lambda_{0}\right)$ suggested by Arrhenius, where $\Lambda$ is the equivalent conductivity of the solution at concentration $\mathrm{M}$, and $\Lambda_{0}$ is that at infinite dilution, Eq. 6 was found satisfactory for dilute electrolyte solutions. As this theory could explain satisfactorily many colligative properties of dilute electrolyte solutions, Arrhenius' theory of electrolytic dissociation gained wide acceptance, and Ostwald's laboratory became a learning center for scientists from far and wide (9).

Nernst (16) also found that the e.m.f. of a concentration cell $(\Delta E)$, e.g., for a dilute 1:1 electrolyte like $\mathrm{NaCl}(\mathrm{aq})$, obeyed the equation,

$\Delta \mathbf{E}=(2 \mathrm{RT} / \mathrm{F}) \ln (\alpha \mathbf{M})$

Heydweiller (17) showed that the changes in volumes/densities of solutions were directly proportional to $\alpha$.

As the conductivity ratio could not explain the properties of solutions at higher concentrations, there were many attempts to obtain the correct degree of dissociation. Suggestions were made by Arrhenius (2c) and by Bousfield (18) that in addition to 
partial dissociation, hydration must be taken into account as in the case of the modifications for non-ideality of the Raoult's law (19) for non electrolytes. The latter law is an ideal law (20) for the vapor pressures of dilute solutions,

$\left(\mathrm{p}_{\mathrm{A}} / \mathrm{p}_{\mathrm{A}}{ }^{0}\right)=\mathrm{N}_{\mathrm{A}}=\mathrm{n}_{\mathrm{A}} /\left(\mathrm{n}_{\mathrm{A}}+\mathrm{n}_{\mathrm{B}}\right)$

where $\left(\mathrm{p}_{\mathrm{A}} / \mathrm{p}_{\mathrm{A}}{ }^{0}\right)$ is the ratio of the vapor pressure $\left(\mathrm{p}_{\mathrm{A}}\right)$ of the solvent (subscript $\left.\mathrm{A}\right)$ over a solution to that $\left(\mathrm{p}_{\mathrm{A}}{ }^{0}\right)$ of the pure solvent, $\mathrm{n}_{\mathrm{A}}$ and $\mathrm{n}_{\mathrm{B}}$ are the number of moles of solvent and solute (subscript $\mathrm{B}$ ) in the solution and $\mathrm{N}_{\mathrm{A}}$ is the mole fraction of the solvent. For a non-electrolyte like sucrose, the deviations from Raoult's law were attributed to hydration (21) and consequent reduction in the number of 'free' (subscript $\mathrm{f}$ ) water molecules (as kinetic entities) from $\mathrm{n}_{\mathrm{A}}$ to $\mathrm{n}_{\mathrm{Af}}=\left(\mathrm{n}_{\mathrm{A}}-\mathrm{n}_{\mathrm{B}} \mathrm{n}_{\mathrm{h}}\right)$, where $\mathrm{n}_{\mathrm{h}}$ is the number of water molecules held as hydration by one mole of the solute.

For an electrolyte like $\mathrm{NaCl}(\mathrm{aq})$, the number of moles of solute changes due to dissociation from $n_{B}=m$ to $n_{B}=i m$, where $i$ is the vant Hoff factor given by Eq. 5 and $\mathrm{m}$ is the molality ( $\mathrm{m}$ moles in one $\mathrm{kg}$ of water) of the solute. Thus Bousfield's (18) suggestion amounted to an equation of the form,

$\left(\mathbf{p}_{\mathrm{A}} / \mathbf{p}_{\mathrm{A}}{ }^{0}\right)=\mathbf{N}_{\mathrm{Af}}=\mathbf{n}_{\mathrm{Af}} /\left(\mathbf{n}_{\mathrm{Af}}+\mathbf{n}_{\mathrm{B}}\right)$

where $\mathrm{N}_{\mathrm{Af}}$ is the mole fraction of free water, $\mathrm{n}_{\mathrm{Af}}=55.51-\mathrm{mn}_{\mathrm{h}}$ is the number of moles of free water, 55.51 is the number of moles of water in one $\mathrm{kg}$ of pure water. The degrees of dissociation estimated from freezing point depressions by Bousfield (18) and the number of free water molecules which he used were still not satisfactory to explain quantitatively the experimental results. 


\section{The existing concepts of activities and complete dissociation of electrolytes}

Lewis and Randall (7) pointed out that the use of the conductivity ratio $\left(\Lambda / \Lambda_{0}\right)$ for the degree of dissociation $(\alpha)$ did not give a constant value (as for weak electrolytes) for the dissociation constant of strong electrolytes. The latter phenomenon came to be known as the 'anomaly of strong electrolytes' (9). Bypassing the question of finding the correct degrees of dissociation, they (7) proposed the 'interim' empirical concepts of activities, activity coefficients and a (pseudo) dissociation constant $\left(\mathrm{K}_{\mathrm{d}}\right)$ as,

$K_{d}=a_{+} \mathbf{a} / a_{B}=1$

where, the activity of the 'undissociated' solute $\left(\mathrm{a}_{\mathrm{B}}\right)$ is equal to the product of the ionic activities, $a_{+} a_{-}=a_{B}$. (Note the basic flaw in Eq. 10: Guldberg and Waage's law for a reversible reaction in equilibrium does not require that $K_{d}=1$ ). In the absence of the knowledge of the ionic activities, they defined a mean ionic activity (for a 1:1 electrolyte) as, $a_{ \pm-}=\left(a_{+} a_{-}\right)^{1 / 2}=m \gamma_{ \pm},=a_{B}{ }^{1 / 2}$ and termed $\gamma_{ \pm}$as the mean ionic activity coefficient $(7,20,22)$. However, as pointed out in (23), the single ionic activities are still 'elusive' quantities.

The vapor pressure ratio was termed (7) solvent activity, $\mathrm{a}_{\mathrm{A}}$, and was related to the osmotic pressure $(7,20)$ by the equations,

$\left(\mathrm{p}_{\mathrm{A}} / \mathrm{p}_{\mathrm{A}}{ }^{0}\right)=\mathrm{a}_{\mathrm{A}}$

$\Delta \mathrm{G}_{\mathrm{A}}=\pi_{\mathrm{os}} V_{A}=\mathrm{vRTm} \phi_{0 s} / 55.51=-\mathrm{RT}^{\mathrm{T}} \mathrm{ln} \mathrm{A}_{\mathrm{A}}$ 
where $\Delta \mathrm{G}_{\mathrm{A}}$ is the solvent free energy, $V_{A}$ is the partial molal volume of the solvent and $\phi_{o s}$ is the non-ideality correction factor called osmotic coefficient $(7,20)$. Note that it is evaluated as, $\phi_{\mathrm{os}}=(55.51 / \mathrm{vm}) \operatorname{lna}_{\mathrm{A}}$, as the excess free energy over the expected value, $v \mathrm{RTm} / 55.51$, for complete dissociation. Thus the experimental data on the vapor pressure ratio, $a_{\mathrm{A}}$, were used for evaluating and tabulating $\phi_{\mathrm{os}}$.

The 'ionic concentration' term, $\alpha \mathrm{M}$, in the Nernst Eq. 7 for a 1:1 electrolyte, was then replaced (7) by the 'mean molal ionic activity', $a_{ \pm-}=m \gamma_{ \pm}$, (replacing $\alpha$ by $\gamma_{ \pm}$)

$\Delta \mathrm{E}=(2 \mathrm{RT} / \mathrm{F}) \ln \left(\gamma_{ \pm} \mathrm{m}\right) ;-\Delta \mathbf{G}_{\mathrm{B}}=2 \mathrm{RT} \ln \left(\mathrm{m} \gamma_{ \pm}\right)$

where $\Delta \mathrm{G}_{\mathrm{B}}$ is the free energy of the solute and $\gamma_{ \pm}$is the mean molal activity coefficient. Note that the latter, a correction factor for non-ideality, is evaluated from the 'unaccounted' difference, $2 \mathrm{RT} \ln \left(\gamma_{ \pm}\right)=\Delta \mathrm{E}-2 \mathrm{RT} \ln (\mathrm{m})$, where $\Delta \mathrm{E}$ is the measured e.m.f. and the last term is the expected value for complete dissociation.. The introduction of the above empiricism into solution chemistry met with strong opposition by many eminent proponents of Arrhenius' theory of partial dissociation. The concentration/activity crisis split the scientists of that period into two groups. Bancroft, the then editor of the Journal of Physical Chemistry, had to defend even the existence of the Journal from near extinction $(\mathrm{see}(9,11 \mathrm{k})$ for opposing the empirical activity concepts.

Around that period, the theory of inter-ionic interaction between free ions in 'very dilute solutions' of completely dissociated electrolytes, e.g., $\mathrm{NaCl}(\mathrm{aq})$, 
by Debye and Huckel $(8,20,22)$, was found to be a good approximation for the observed dependence of $\Delta \mathrm{E}$ and other properties (like equivalent conductivity, molal volumes, etc.) on the square root of $\mathrm{M}$. This was taken (erroneously) to imply support for the empirical activity coefficients and complete dissociation of electrolytes at all concentrations $(20,22)$. (Note: In the latter case, the activity of the undissociated electrolyte $\mathrm{a}_{\mathrm{B}}=0$ and the equilibrium constant given by Eq. 10 loses significance). Subsequently both $\phi_{o s}$ and $\gamma_{ \pm}$were evaluated using Eqs. 12 and 13 and tabulated assuming completing dissociation of electrolytes at all concentrations, and they became known as the 'thermodynamic' non-ideality correction factors. Thus Lewis and Randall (7) advocated the above empirical concepts avoiding the question of the state of the electrolytes as 'partially' or 'completely' dissociated.

Subsequently, since increasing evidence showed that there is ion association in multivalent electrolytes, Bjerrum $(24,20)$ derived an expression for their degrees of association at various concentrations. However, he also thought that for 1:1 strong electrolytes ionic association was unlikely since the critical distance for ion pair formation was too large.

The Debye-Huckel equations were then gradually tailored and extended with more and more empirical parameters to fit the data for higher and higher concentrations up to saturation $(20,22,25,26)$ for all electrolytes. To give some examples, say from (25), the concentration dependence of $\gamma_{ \pm}$is expressed by,

$$
\begin{aligned}
& \ln \left(\gamma_{ \pm}\right)=-z_{M} Z_{X} A_{\phi}\left[\left(I^{1 / 2} /\left(1+b I^{1 / 2}\right)+(2 / b) \ln \left(1+b I^{1 / 2}\right)\right]+\right. \\
& m\left(2 v_{M V X} / v\left\{2 \beta_{M X}{ }^{(0)}+\left(2 \beta_{M X}(1) / \alpha^{2} I\right)\left[1-\left(1+\alpha I^{1 / 2}-\alpha^{2} I / 2\right) \exp \left(-\alpha I^{1 / 2}\right)\right]\right\}+\right. \\
& m^{2}\left(2 v_{M}^{2} v_{X} z_{M} / v\right)\left(3 C_{M X}\right)
\end{aligned}
$$


where $\alpha$ is a parameter and not the degree of dissociation. See (24) for the explanation of various parameters.

A similar elaborate equation (25) holds for the osmotic coefficient, $\phi_{o s}$,

$$
\begin{aligned}
& \phi_{o s}=1-z_{M} Z_{X} A_{\phi} I^{1 / 2} /\left(1+b I^{1 / 2}\right)+m\left(2 v_{M} v_{X} / v\right)\left(\beta_{M X}^{(0)}+\beta_{M X}^{(1)} \exp \left(-\alpha I^{1 / 2}\right)+\right. \\
& m^{2}\left(4 v_{M}{ }^{2} v_{X} Z_{M} / v\right) C_{M X}
\end{aligned}
$$

Another complex equation holds for the partial molal volume of solutions (26),

$V_{\phi_{I} M X}=\left(V_{m}-V_{A}{ }^{0}\right) / m=V_{M X}{ }^{0}+A_{0}+A_{1} \beta_{M X}{ }^{(0) V}+A_{2} \beta_{M X}{ }^{(1) V}+A_{3} \beta_{M X}{ }^{(2) V}+A_{4} C_{M X}{ }^{V}$

Thus the theory of electrolytes was translated into many parametric equations and empirical concepts which gave no insight into the molecular phenomena responsible for the experimental data. Moreover, these gave no uniform concept of non-ideality for the thermodynamic properties of solutions over the whole concentration range. See $(10 a-d)$ for some more criticisms.

\section{The successful revival of the Arrhenius' theory of electrolytic dissociation}

The present author, while analyzing the dependence on concentration of the polarographic half wave potentials due to adsorption found its similarity to the Yesin-Markov shifts of the potentials of zero charge (11a). This indicated that the underlying solution thermodynamics was common to both and pointed to the correctness of the long abandoned van Hoff factor $(11 b)$. This made the author analyze afresh the existing experimental data on the physico-chemical properties of electrolytes, and to eventually arrive at the conclusion that the earlier theory of 
partial dissociation due to Arrhenius is, in fact, correct (11-13). On using the degrees of dissociation evaluated from the vapor pressure data, instead of from the conductivity ratio (2) or the freezing point depression (18), the author found that thermodynamic properties could be explained quantitatively gradually from zero all the way up to saturation (11e), based on the only two causes of non-ideality, 'partial dissociation and hydration' as suggested originally by Arrhenius (2c) and Bousfield (18). The details can be found in (11-13). The author also obtained the first time experimental support for the presence of electrostatic ion pairs in the work on X-ray diffraction studies of saturated alkali halide solutions, by Ohtaki and Fukushima (27).

Given below are some of the simple equations found valid for the solution properties of the common salt based on partial dissociation and hydration at all concentrations, see $(11 e-j, 12)$ for all the details.

1) Interpretation of vapor pressure and osmotic pressure in terms of partial dissociation and 'surface' and 'bulk' hydration numbers (11e):

$$
\begin{aligned}
& \left(\mathbf{p}_{\mathrm{A}} / \mathbf{p}_{\mathrm{A}}{ }^{0}\right)=\mathbf{n}_{\mathrm{Afs}} /\left(\mathbf{n}_{\mathrm{Afs}}+\mathrm{im}\right)=\mathbf{N}_{\mathrm{Afs}}\left[=\mathbf{a}_{\mathrm{A}}\right. \text { of Eq. 11] } \\
& \pi_{\mathrm{os}}=\mathrm{iRT} / \mathrm{V}_{\mathrm{Afb}}=\left[=-\mathrm{RT} \ln \mathrm{a}_{\mathrm{A}} / V_{A}\right. \text { of Eq. 12] } \\
& -\mathbf{a}_{\mathrm{A}} \ln \mathbf{a}_{\mathrm{A}} /\left(1-\mathbf{a}_{\mathrm{A}}\right)=\left(\mathbf{n}_{\mathrm{Afs}} / \mathbf{n}_{\mathrm{Afb}}\right) \\
& -\operatorname{lna} a_{A}=\left(\pi_{o s} V_{A} / R T\right)=2 m \phi_{o s} / 55.51=\left(N_{B} / N_{\text {Afs }}\right)\left(n_{\text {Afs }} / \mathbf{n}_{\text {Afb }}\right)=i m / n_{A f b}
\end{aligned}
$$

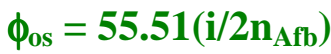

where $\mathrm{n}_{\mathrm{Afs}}=\left(55.51-\mathrm{mn}_{\mathrm{s}}\right), \mathrm{n}_{\mathrm{Afb}}=\left(55.51-\mathrm{mn}_{\mathrm{b}}\right)$ are the molalities of free water at the 'surface' and 'bulk' (subscripts s and b), which concern respectively, the vapor pressure (surface property) and osmotic pressure (a bulk property), $\mathrm{n}_{\mathrm{s}}$ and $\mathrm{n}_{\mathrm{b}}$ are 'surface' and 'bulk' hydration numbers and $\mathrm{V}_{\mathrm{Afb}}=\mathrm{n}_{\mathrm{Afb}} \mathrm{V}_{\mathrm{A}}{ }^{\mathrm{o}}$, is the volume of free water 
in the bulk and $\mathrm{v}_{\mathrm{A}}{ }^{\mathrm{o}}$ is the volume of one mole of water. The values of $\mathrm{n}_{\mathrm{s}}, \mathrm{n}_{\mathrm{b}}$ and $\alpha$ can be obtained by using the available data on $\mathrm{a}_{\mathrm{A}}\left(\right.$ or $\left.\phi_{\mathrm{os}}\right)$ as described in (11e) and (12). (Note that osmotic coefficient simply stands for the ratio given by Eq. 22 unlike in Eq. 16.) The degree of dissociation $\alpha$ decreases with increasing $m$ from a value of unity at infinite dilution to a minimum at about $1.5 \mathrm{~m}$ and then increases to a limiting value at saturation, see (11e). The actual ionic molalities, $\alpha \mathrm{m}$ and the molality of the ion pairs, (1- $\alpha) \mathrm{m}$ could thus be obtained for many strong electrolytes (13).

Figure 1 shows an example of the difference between the mean ionic activity $\left(\gamma_{ \pm} \mathrm{m}\right)$ and the actual ionic molality $(\alpha \mathrm{m})$ from 'zero to saturation' for $\mathrm{NaCl}$ at $25{ }^{\circ} \mathrm{C}$.

The 'surface' and 'bulk' hydration numbers for forty two 1:1 strong electrolytes were found to be related by the linear equation, see the Table and graph in $(11 \mathrm{~g})$,

$\mathbf{n}_{\mathrm{s}}=\mathbf{1 . 0 0 7} \mathrm{n}_{\mathrm{b}}+\mathbf{0 . 8 8}$

where 0.88 is a constant and is the fraction of a molecule of bound water independent of the type of the electrolyte. This excess surface hydration could perhaps be related to the hydrogen bonding at the vapor/liquid interface (29).

2) Interpretation of the e.m.f. of concentration cells and the mean ionic activity $\left(\gamma_{ \pm} \mathrm{m}\right)$ from $\sim 0.001 \mathrm{~m}$ to saturation in terms of partial dissociation and hydration:

$$
\begin{aligned}
& \Delta \mathrm{E}=-(2 \mathrm{RT} / \mathrm{F}) \ln \left(\gamma_{ \pm} \mathrm{m}\right)=-\delta_{\mathrm{A}}(2 \mathrm{RT} / \mathrm{F}) \ln \left[\left(\alpha \mathrm{m} / \mathrm{n}_{\mathrm{Afs}}\right) / \mathrm{r}_{\mathrm{s}}{ }^{0}\right] \\
& \ln \left(\gamma_{ \pm} \mathrm{m}\right)=-\mathrm{F} \Delta \mathrm{E} / 2 \mathrm{RT}=\delta_{\mathrm{A}} \ln \left[\left(\alpha \mathrm{m} / \mathbf{n}_{\mathrm{Afs}}\right) / \mathbf{r}_{\mathrm{s}}{ }^{0}\right]
\end{aligned}
$$


where $\mathrm{n}_{\mathrm{Afs}}=\left(55.51-\mathrm{mn}_{\mathrm{s}}\right),\left(\alpha \mathrm{m} / \mathrm{n}_{\mathrm{Afs}}\right)=\mathrm{r}_{\mathrm{s}}$, and $\delta_{\mathrm{A}}$ is a solvent-solute polarization factor (28) obtained as the slope of $\Delta \mathrm{E}$ vs $\operatorname{lnr}_{\mathrm{s}}$ straight line, $\mathrm{r}_{\mathrm{s}}{ }^{\mathrm{o}}=\left(\alpha \mathrm{m} / \mathrm{n}_{\mathrm{Afs}}\right)^{\mathrm{o}}$ for $\Delta \mathrm{E}=0$ and $\Delta \mathrm{E}^{\mathrm{o}}=\delta_{\mathrm{A}}(2 \mathrm{RT} / \mathrm{F}) \ln \mathrm{r}_{\mathrm{S}}^{\mathrm{o}}$.

Figure 2 shows the linear dependence of $\ln \left(\gamma_{ \pm} m\right)$ on $\ln [(\alpha \mathrm{m})$ as per Eq. 24 , with slope $=\delta_{\mathrm{A}}=0.957$ and intercept, $\ln \mathrm{r}_{\mathrm{s}}{ }^{\mathrm{O}}=3.592$ for $\mathrm{NaCl}(\mathrm{aq})$ at $25{ }^{0} \mathrm{C}$. This shows that $\Delta \mathrm{E}$ is directly proportional to $\ln \left(\alpha \mathrm{m} / \mathrm{n}_{\mathrm{Afs}}\right)$, and also that the empirical mean ionic activity $\left(\gamma_{ \pm} \mathrm{m}\right)$ and complicated Eq. 15 for $\ln \left(\gamma_{ \pm}\right)$are not needed anymore. This linearity has been confirmed for many electrolytes, (13).

Note that in the case of hydrogen ion concentrations, $\mathrm{p}[\mathrm{H}]=-\ln [\mathrm{H}]=-\ln$ $\left(\alpha \mathrm{m} / \mathrm{n}_{\mathrm{Afs}}\right)$, whereas $\mathrm{p}\left(\mathrm{a}_{\mathrm{H}+}\right)=-\ln \left(\gamma_{ \pm} \mathrm{m}\right)$, which differ $(11 \mathrm{~g})$.

3) Interpretation of the molal volumes, $V_{m}$ in terms of partial dissociation: The molal volumes, $\mathrm{V}_{\mathrm{m}}$ are given by $(11 e, g, h, 12)$,

$$
\begin{aligned}
& \left.V_{m}-V_{A}{ }^{o}=m\left[(1-\alpha) V_{B}{ }^{o}+\alpha \phi_{v}{ }^{0}\right)\right] ; \\
& V_{m}-V_{A}=\alpha m\left(\phi_{v}{ }^{o}+\delta V_{d}\right)=\alpha m\left(V_{B}{ }^{o}+\delta V_{e l}\right) ;\left(m>m_{\alpha \min } \text { up to satn. }\right)
\end{aligned}
$$

where $\mathrm{V}_{\mathrm{A}}{ }^{\mathrm{o}}$ is the volume of $1 \mathrm{~kg}$ of water in the pure state; $\mathrm{V}_{\mathrm{B}}{ }^{\mathrm{o}}$ is the volume of one mole of the pure electrolyte, $\phi_{\mathrm{v}}{ }^{\circ}=\left(\mathrm{V}_{+}+\mathrm{V}_{-}+\delta \mathrm{V}_{\mathrm{el}}\right) ; \mathrm{V}_{+}+\mathrm{V}_{-}$is the sum of the volumes per mole of the ions, $\delta \mathrm{V}_{\mathrm{el}}$ is the electrostriction, $\delta \mathrm{V}_{\mathrm{d}}=\mathrm{V}_{\mathrm{B}}{ }^{\mathrm{o}}-\left(\mathrm{V}_{+}+\mathrm{V}_{-}\right)$and $\mathrm{V}_{\mathrm{A}}<\mathrm{V}_{\mathrm{A}}{ }^{\circ}$. Thus, changes in the volumes of solution are due to $\alpha \mathrm{m}, \delta \mathrm{V}_{\mathrm{d}}$ and $\delta \mathrm{V}_{\mathrm{el}}$. Note the complicated Eq. 17 based on complete electrolytic dissociation in comparison with the simple Eqs. 26a,b.

Further work on the volumes of ions and ion pairs in aqueous solutions $(30 a, b)$ and on hydrogen bonding (30c) have brought new insights. 
4) Interpretation of the dissociation constant. For the ionic dissociation equilibrium given by Eq. 3, the dissociation constant is given by $(11 g, 12)$,

$\mathbf{K}_{\mathrm{d}}=\left\{\left(\alpha \mathbf{m} / \mathbf{V}_{\mathrm{i}}\right)^{2} /\left[(1-\alpha) \mathrm{m} / \mathbf{V}_{\mathrm{ip}}\right]\right\}_{\mathrm{soln}}=\mathbf{K}_{\mathrm{cr}}=\left[\mathrm{V}_{\mathrm{cr}} /\left(\mathrm{V}_{+}+\mathbf{V}_{-}\right)^{2}\right]_{\mathrm{cr}}=\mathrm{const}$

where $V_{i}$ and $V_{\text {ip }}$ are volumes of solution occupied by the ions and ion pairs respectively, $\left(\alpha \mathrm{m} / \mathrm{V}_{\mathrm{i}}\right)$ and $(1-\alpha) \mathrm{m} / \mathrm{V}_{\mathrm{ip}}$ are the concentrations of the ions and ion pairs and $\mathrm{V}_{\mathrm{cr}}$ and $\left(\mathrm{V}_{+}+\mathrm{V}_{-}\right)$are the volumes per mole of the crystal and ions respectively. For $\mathrm{NaCl}(\mathrm{aq})$ at $25^{\circ} \mathrm{C}, \mathrm{K}_{\mathrm{d}}=0.080 \mathrm{~mol} . \mathrm{cm}^{-3}$ from "zero to saturation". Thus, $\mathrm{NaCl}$ and similar electroytes dissociate in solution such that $\mathrm{K}_{\mathrm{d}}=\mathrm{K}_{\mathrm{cr}}=$ constant, which demonstrates the simple and beautiful workings of Nature.

Note thus that the pseudo Eq. 10 is replaced by the meaningful Eq. 27.

5) Bjerrum's theory of ionic association found applicable for 1:1 strong electrolytes: Since now the degrees of dissociation for 1:1 electrolytes are known (11-13), the author used Bjerrum's equation $(24,20)$,

$(1-\alpha)=[2.755 \mathrm{f}(\mathrm{a})] \mathrm{c}$

where $f(a)$ is a function of the mean distance of closest approach, a, of the oppositely charged ions, to calculate (for the first time) the distance, a, for $\mathrm{NaCl}(\mathrm{aq})$ from "zero to saturation" $(11 i, j)$. The value of a was found to increase from $1.85 \AA$ at $0.1 \mathrm{~m}$ to $3.53 \AA$ at saturation. The latter is close to the critical distance of approach, $\mathrm{q}=3.57 \AA$ (20), predicted by Bjerrum for ion association. Thus Bjerrum's equation was shown to be useful for evaluating the mean distance of closest approach of ions in solutions 
of 1:1 electrolytes. Note that Bjerrum thought on the contrary that since $q=3.57 \AA$, it is too large for ion association in 1:1 strong electrolytes.

6) Equation of state for solutions incorporating thermodynamics: A concise equation of state for aqueous electrolyte solutions (31), analogous to those for gases (32), incorporating thermodynamic properties like the heat capacities was established.

$\pi_{\text {os }}\left(\mathbf{V}_{\mathrm{A}}-\mathrm{V}_{\mathrm{h}}\right) / \mathrm{i}=\pi \mathrm{V}_{\mathrm{Af}}=\left(\mathrm{C}_{\pi \mathrm{f}}-\mathrm{C}_{\mathrm{Vf}}\right) \mathrm{T}=\mathrm{RT}$

where $\pi_{\mathrm{os}}$ and $\mathrm{V}_{\mathrm{A}}$ are the osmotic pressure and total volume of water (A) respectively of a solution containing one mole of solute at temperature $\mathrm{T}, \mathrm{i}[=1+(\nu-1) \alpha]$ is the van't Hoff factor (for non-electrolytes $\mathrm{i}=1$ ), $\mathrm{V}_{\mathrm{h}}$ is the volume of water held a hydration, $\mathrm{V}_{\mathrm{Af}}$ is the free (subscript $\mathrm{f}$ ) volume of solvent per mole of solute. The heat capacity at constant osmotic pressure $\left(\mathrm{C}_{\pi \mathrm{f}}\right)$ and constant volume $\left(\mathrm{C}_{\mathrm{Vf}}\right)$ respectively, are defined here on the free volume per mole basis. The ideal heat capacity difference is equal to the gas constant, R. Note that the ideal law and Eq. 29 here are of the same form but with $\mathrm{V}_{\mathrm{Af}}$ in place of $\mathrm{V}$ (the volume of solution in the case of ideal law).

Since the molar entropy $\mathrm{S}=\mathrm{R} \ln \mathrm{W}$, where $\mathrm{W}$ is the maximum probablity of existence at the given $\pi_{\mathrm{os}}, \mathrm{V}_{\mathrm{Af}}$ and $\mathrm{T}$, on combining this with Eq. 29, one obtains,

$Q_{s}=T S=R T \ln W=\pi_{\text {os }} V_{\text {Af }} \ln W$

Thus, entropy, heat capacities and the thermodynamic laws are integral parts of the new equation of state, Eq. 29. For more details, see (31). 
8) List of Tables of data: Degrees of dissociation $(\alpha)$ of strong electrolytes at various molalities $(\mathrm{m})$ in aqueous solutions at $25^{\circ} \mathrm{C}$ and surface $\left(\mathrm{n}_{\mathrm{s}}\right)$ and bulk $\left(\mathrm{n}_{\mathrm{b}}\right)$ hydration numbers.

1) Sodium chloride: see (11e)

2) All alkali halides: see (11f)

3) All halogen acids, perchloric acid, nitric acid; all alkali hydroxides, lithium perchlorate, sodium perchlorate; all alkali nitrates, sodium thiocyante, potassium thiocyanate; all alkali acetates and ammonium chloride: see $(11 g, 13)$

4) All monovalent sulfates: see $(11 l, 13)$

Support for the author's above work: The author's work has gained support in the form an invitation to contribute to two books $(30 b, 33)$, a review of a talk (34), an invitation for the plenary talk (12) and from other researchers, e.g., (35 - 38).

Acknowledgments The author is grateful to the Institute of Biophysics of the Academy of Sciences of the Czech Republic (ASCR) for financial and moral support. Special thanks for encouragement are due to many scientists here and abroad and to the staff of the Chemical Heritage Foundation, Philadelphia for providing the access to relevant literature.

\section{References}

1. Kurlansky, M. Salt, A World History, Walker and company, New York, 2002

2. S. Arrhenius, S. a) Z. Physik. Chem. 1887, I, 631.

b) http://www.nobelprize.org/nobel_prizes/chemistry/laureates/1903/arrheniusbio.html 
c) J. Am. Chem. Soc. 1912, 34, 353.

d) http://en.wikipedia.org/wiki/Svante_Arrhenius

3. Crawford, E. T. Arrhenius: from ionic theory to the greenhouse effect, Canton, MA; Science History Publications, USA, 1996.

4. Arrhenius, G., Caldwell, K., Wold, S. A Tribute to the Memory of Arrhenius (1859-1927), A Scientist Ahead of His Time, OH-Tryck, Stockholm, Sweden, 2008. http://www.iva.se/upload/Verksamhet/Högtidssammankomst/Minnesskrift\%202008. $\underline{\mathrm{pdf}}$

5. Törnebladh, H. R.

http://nobelprize.org/nobel_prizes/chemistry/laureates/1903/press.html

6. Waage, P. and Guldberg, C. M. Forhandlinger: Videnskabs-Selskabet i Christiana 1864, 35; from: http://chimie.scola.ac-

$\underline{\text { Paris.fr/sitedechimie/hist_chi/text_origin/guldberg_waage/Concerning-Affinity.htm }}$ 7. Lewis, Randall, M. J. Amer. Chem. Soc. 1921, 43, 1112.

8. Debye, P., Hückel, E. Phys. Zeit., 1923, 24, 185.

9. Servos, J. W. Physical Chemistry from Ostwald to Pauling, The making of a science in America, Princeton Univ Press, New Jersey, $2^{\text {nd }}$ printing, 1996.

10. a) Darvell, B. W., Leung, V. W.-H. Chem. Brit. 1991, 27, 29,

b) Franks, F. Chem. Brit. 1991, 27. 315,

c) Heyrovska, R. Chem. Brit. 1991, 27. 1114,

d) C. B. Monk, C. B. Chem. Brit. 1993, 29, 1033.

11. Heyrovska, R. a) Extended Abstracts, 155th Meeting of Electrochemical Society, USA, Boston, 1979, 79-1, abstract no. 354

b) Extended Abstracts, 157th Meeting of Electrochemical Society, USA, St. Louis, 1980, 80-1, abstract no. 526. 
c) Collec. Czechosl. Chem. Comm. 1988, 53, 686.

d) A Reappraisal of Arrhenius' Theory of Partial Dissociation of Electrolytes. In Electrochemistry. Past and Present, Stock J. T., Orna, M. V., Eds.; ACS Symposium Series No. 390. Washington. DC. 1989, chapter 6.

e) J. Electrochem. Soc. 1996, 143, 1789; 187th Mtg of the Electrochemical Society, USA, Reno, USA, Vol. 95-1 (1995) abstract no.662 (Extended abstract)

f) Croat. Chem. Acta 1997, 70. 39; Special Issue in honor of Marco Branica.

g) Chemicke Listy 1998, 92, 157,

h) 217th National Meeting of the American Chemical Society, Anaheim, March 1999, abstract no. 61; Marine Chemistry, 2000, 70, 49. (Proceedings, Dedicated to Frank J. Millero on the occasion of his 60th birthday)

i) J. Molec. Liq. 1999, 81, 83;

j) Current Science 1999, 76, 179, http://www.ias.ac.in/currsci/jan25/articles23.htm (accessed last: 7th Nov. 2009)

k) 219th Meeting of The American Chemical Society, San Francisco, March 2000, abstract no. 37 .

1) 1999 Joint International Meeting (196th Meeting of The Electrochemical Society, USA, 1999 Fall Meeting of The Electrochemical Society of Japan with technical cosponsorship of The Japan Society of Applied Physics), Honolulu, Hawaii, October 1999, short abstract no. 2041. Extended abstract:

http://www.electrochem.org/dl/ma/196/pdfs/2041.PDF(1999)

12. Heyrovska, R., Plenary talk: Symposium Svante Arrhenius, commemorating the $100^{\text {th }}$ Anniversary of the Award of the Nobel Prize to Arrhenius, Uppsala, November 2003: http://www.jh-inst.cas.cz/ rheyrovs/text-sa-.htm

13. Heyrovska, R. Electroanalysis, 2006, 18, 351. 
14. Ostwald, W. Z. Physik. Chem. 1888, 2, 270.

15. van't Hoff, J. H. Z. Physik. Chem. 1887, I, 481.

16. Nernst, W., Z. Phys. Chem. 1889, 4, 155.

17. Heydweiller, A. Z. Physik. Chem. 1910, 70, 128.

18. Bousfield, W. R. Trans. Faraday Soc. 1917, 13, 141.

19. Raoult, F. M. Z. Physik. Chem. 1888, 2, 353.

20. Robinson, R. A., R. H. Stokes, R. H. Electrolyte Solutions, Butterworths, London, 1955 \& 1970.

21. Porter, A. W. Trans. Faraday Soc. 1917, 13, 123.

22. Harned, H. S., Owen, B. B. The Physical Chemsitry of Eletrolytic Solutions, Rheinhold, New York, 1958.

23. Bates, R. G. Pusuit of the Elusive Single-Ion Activity. In Electrochemistry. Past and Present, Stock J. T., Orna, M. V. Eds.; ACS Symposium Series No. 390. Washington. DC. 1989, chapter 10.

24. Bjerrum, N. K. Danske Vidensk. Selsk. 1926, 7; Proc. 7th Internl. Congr. of Appl. Chem., London. 1909, 55; from (19).

25. Archer, D. G. J. Phys. Chem. Ref. Data 1991, 20. 509; 1992, 21, 1; 1999, $28,1$. 26. a) Pitzer, K. S., Peiper, J. C., Bussey, R. H. J. Phys. Chem. Ref. Data 1984, 13, 1 b) Krumgalz, R., Pogorelsky, R., Pitzer, K. S. J. Phys. Chem. Ref. Data 1996, 25, 663.

27. a) Ohtaki, H., Fukushima, N. J. Solution Chem. 1992, 21, 23,

b) Ohtaki, H. Pure Appl. Chem. 1993, 65, 203.

28. Conway, B. E., Marshall, S. Aust. J. Chem. 1983, 36, 2145.

29. Stiopkin, I.V., Weeraman, C., Pieniazek, P.A., Shalhout, F.Y., Skinner, J.L., Benederskii, A.V., Nature, 2011, 474, 192-195; 
http://www.nature.com/nature/journal/v474/n7350/full/nature10173.html

30a. Heyrovska, R. Chem. Phys. Letts., 2006, 429, 600.

b. Chapter 12 in: Innovations in Chemical Biology, Editor: Bilge Sener,

Springer.com, January 2009; (Proceedings of the $9^{\text {th }}$ EurasiaConference on Chemical

Sciences, Antalya, Turkey, September 2006).

c. Chem. Phys. Letts. 2006, 432, 348.

31. Heyrovska, R. Entropy 2004, 6, 128:

http://mdpi.net/entropy/papers/e6010128.pdf (accessed last: 7th Nov. 2009)

32. Heyrovská, R. In Quantum Limits to the Second Law, First International

Conference, AIP Conference Proceedings No. 643, Editor: Sheehan, D. P., San

Diego, California, 2002, pp 157 - 162; and the literature therein

33. Heyrovska, R. Notes on Hydration Theory. In: Ionic Equilibrium, Butler, J. N.,

Ed; John Wiley and Sons, New York, 1998, chapter 11.

34. Orna, M. V. Chem. Heritage Mag. 2000, 18, 29.

35. de Berg, K.C. Science and Education 2003, 12, 397, b)

The Arrhenius Story: More than a Legend from the Past. In: Proceedings of the

Second International Conference on Story in Science Teaching. July, 2008, Munich, Germany: http://www.sci-ed.org/Conference-2008/deBerg.pdf

36. Loehe, J. R., Donohue, M. D. AIChE Journal, 2004, 43, 180.

37. Minofar, B., Vacha, R., Wahab, A., Mahiuddin, S., Kunz, W., Jungwirth, P. J. Phys. Chem. B, 2006, 110 (32), 15939.

38. Gopalakrishnan, S., Liu, D., Allen, H. C., Kuo, M., Shultz, M. J.

Chem. Rev., 2006, 106 (4), 1155. 


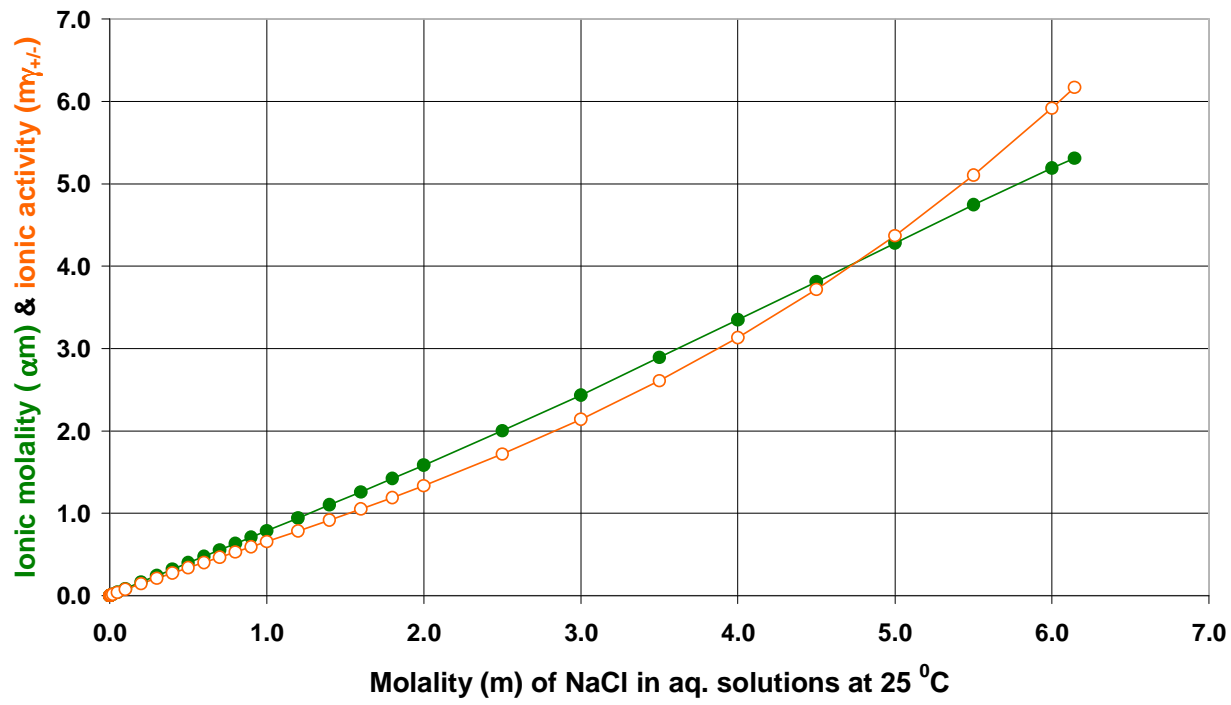

$-\bullet$ Ionic molality $-0-$ Ionic activity

Figure 1 . Ionic molality $(\alpha \mathrm{m})$ and ionic activity $\left(\mathrm{m} \gamma_{+/-}\right)$vs molality $(\mathrm{m})$ of $\mathrm{NaCl}$ in aq. solutions at $25{ }^{0} \mathrm{C}$ from zero to saturation $(6.14 \mathrm{~m})$

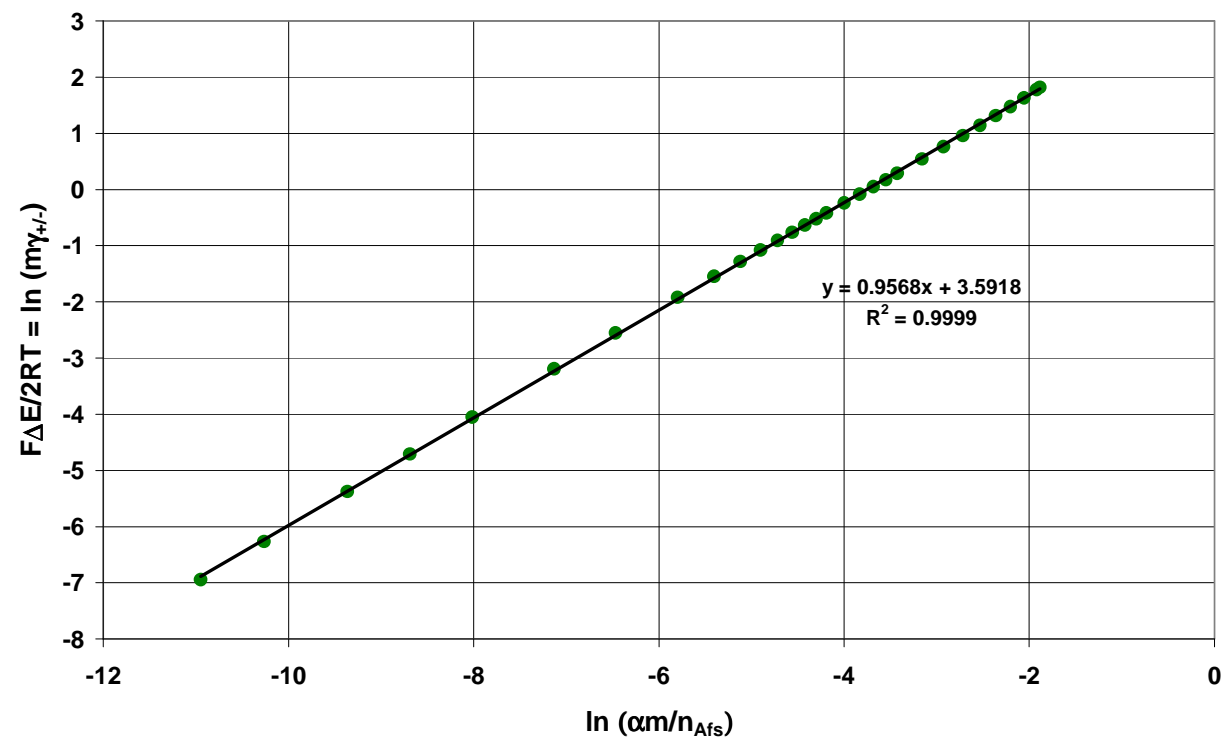

Figure 2. Linear dependence of $(\mathrm{F} \Delta \mathrm{E} / 2 \mathrm{RT})$ on $\ln \left(\alpha \mathrm{m} / \mathrm{n}_{\mathrm{Afs}}\right)$ for aq. solutions of $\mathrm{NaCl}$ at $25{ }^{0} \mathrm{C}$ from $0.001 \mathrm{~m}$ to saturation $(6.14 \mathrm{~m})$, (slope $\left.=\delta_{\mathrm{A}}\right)$. This graph also shows the total replacement of mean ionic activity, $\mathrm{a}_{+/-}(=\mathrm{m} \gamma+/-)$ by $\left(\alpha \mathrm{m} / \mathrm{n}_{\mathrm{Afs}}\right)$. 